\title{
Comparative study of indoor-outdoor exposure against volatile organic compounds in South and Middle America
}

\author{
O. Herbarth ${ }^{1}$, A. Müller ${ }^{2}$, L. Massolo ${ }^{3} \&$ H. Tovalin ${ }^{4}$ \\ ${ }^{I}$ Department Environmental Medicine and Hygiene, Faculty of Medicine, \\ University of Leipzig, D-04103 Leipzig, Germany \\ ${ }^{2}$ UFZ-Centre for Environmental Research, \\ Department of Human Exposure Research and Epidemiology, \\ D-04318 Leipzig, Germany \\ ${ }^{3}$ Centro de Investigaciones del Medio Ambiente, \\ Facultad de Ciencias Exactas, Universidad Nacional de La Plata, \\ Argentina \\ ${ }^{4}$ División de Estudios de Posgrado e Investigación, FES-Zaragoza, \\ Universidad Nacional Autónoma de México (UNAM), México D.F., \\ Mexico
}

\begin{abstract}
Volatile organic compounds (VOCs) play an important role in indoor and outdoor air pollutants. In the present study, samples were analyzed from indoor (schools and houses) and outdoor air in urban, industrial, semi-rural and residential areas from Argentina (La Plata region) and Mexico (Mexico City region) to consider VOC exposure in different types of environments. VOCs were sampled using a passive sampling method with passive $3 \mathrm{M}$ monitors. Samples were extracted with $\mathrm{CS}_{2}$ and analyzed by GC/MS detectors.

The results show significant differences in concentration and distribution between indoor and outdoor samples, depending on the study area. Most VOCs predominantly originated indoors influenced by local outdoor emissions (traffic and industry).
\end{abstract}

Keywords: VOCs, indoor-outdoor ratio, urban and industrial burdens, indoor sources. 


\section{Introduction}

Volatile organic compounds (VOCs), arising from natural and anthropogenic processes represent an important group of indoor and outdoor air pollutants, because they are ubiquitous and associated with increased long-term health risks $[1,2]$, for the general population and those people that stay outdoors for a long time [3]. Vehicular and industrial emissions are the major sources of outdoor VOCs. It has been estimated that $35 \%$ of total VOC emissions are due to vehicle exhaust and evaporative losses [4-6].

Indoor VOC exposure is thought to be of greater concern in the community because indoor concentrations of many pollutants are often higher than those typically encountered outdoors. At the same time, indoor VOC concentration may be the dominant contributor to personal exposure because most people spend over $80 \%$ of their time indoors, either in the home or in the work place $[7,8]$. Measurement of VOCs in the indoor environment has received substantial research attention for several years because indoor VOC levels may pose potential health effects to occupants of dwellings. While some VOCs may be present at concentrations that are not considered acutely harmful to human health with short-term exposure, long-term exposure may result in mutagenic and carcinogenic effects.

The occurrence and concentrations of VOCs in residences can be affected by outdoor atmospheric conditions, indoor sources, indoor volume, human activities, chemical reactions, ventilation rates, and seasonal factors $[9,10]$.

Indoor sources are quite numerous including combustion products, cooking, construction materials, furnishings, paints, varnishes and solvents, adhesives and caulks, office equipment and consumer products [11-13].

To consider the VOC exposure in the different types of environments, measurements of VOC concentrations were carried out indoors and outdoors in areas influenced by industrial emissions, in an urban area influenced by traffic, as well as in semi-rural and residential areas as control and as an area influenced by emissions coming from the (mega)-city. The indoor-outdoor ratios were calculated to get an impression regarding the sources of VOC exposure and the impact of outdoor-related air pollution on the indoor environment.

\section{Methods}

\subsection{Measurement sites}

The study region, La Plata and neighboring areas, located northeast of Buenos Aires province (Argentina), has a population around 700,000 inhabitants. Four sampling zones were considered: industrial (I), urban (U), semi-rural (SR) and residential (R) areas (Figure 1).

The industrial area holds the country's main oil refinery (total crude oil distillation capacity: $38,000 \mathrm{~m}^{3} / \mathrm{day}^{-1}$ ) located next to six petrochemical plants producing diverse compounds such as aromatics (benzene, toluene, xylenes), aliphatic solvents (n-pentane, n-hexane, n-heptane), polypropylene, polybutene, 
maleic anhydride, cyclohexane, methanol, methyl tertiary butyl ether, and petroleum coke. This industrial complex is approximately $10 \mathrm{~km}$ north-northeast of the main urban sector of the city.

The urban area is characterized by heavy traffic; the number of vehicles registered is approximately 200,000 . The semi-rural and residential sites, places with low traffic, were considered control areas.

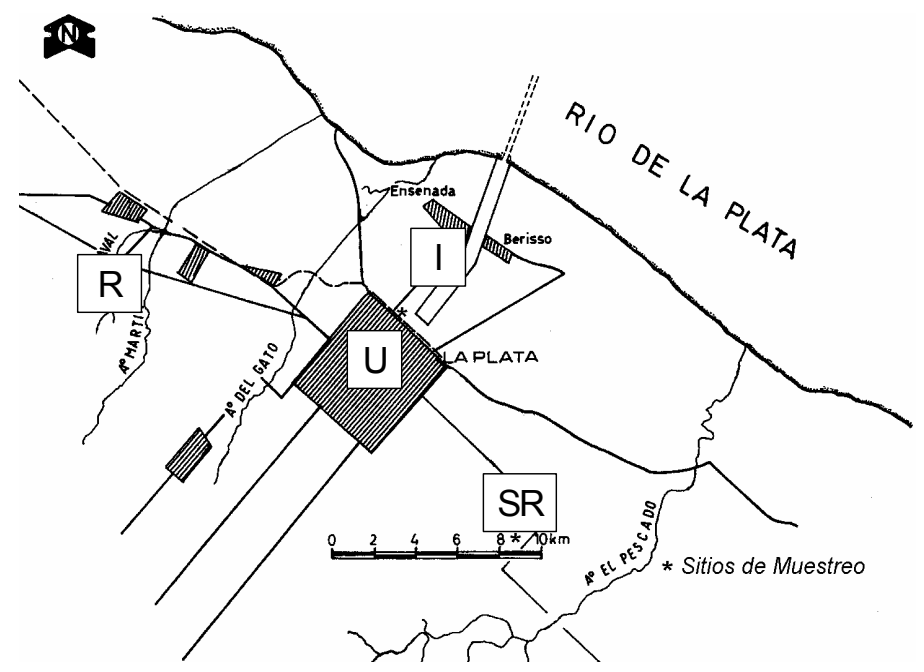

Figure 1: $\quad$ Sampling points in La Plata (I, industrial; U, urban; SR, semirural; $\mathrm{R}$, residential).

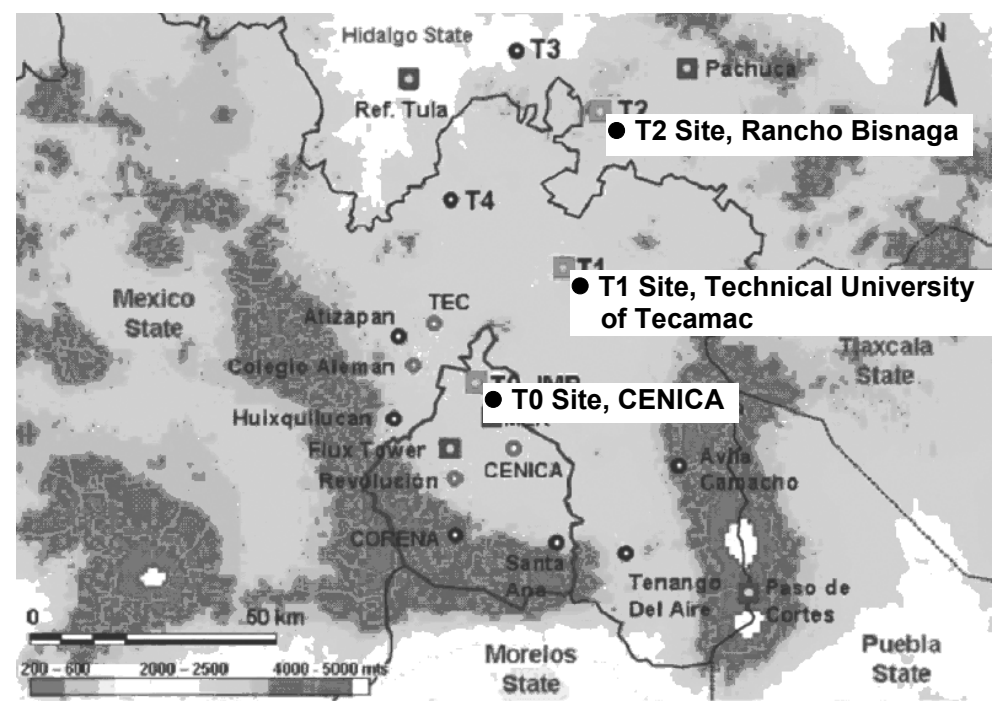

Figure 2: $\quad$ Sampling points in Mexico (T0 urban, T1 suburban, T2 rural). 
The Mexico study is part of the MILAGRO project (Megacity Initiative: Local and Global Research Observations) [16]. The air pollution problem in megacities is influenced by several factors that include the topography, meteorology, demographic growth, industrial growth and urban expansion.

The Mexico City Metropolitan Area (MCMA) - the second largest megacity in the world - has an estimated population of 18 million people and covers an urbanized area that totals $1,500 \mathrm{~km} 2$, encompassing the 16 delegations of the Federal District, 37 municipalities of the State of Mexico and 1 municipality of the State of Hidalgo. In the MCMA, emissions of pollutants reach millions of tons per year, and atmospheric concentrations of ozone and particulate matter routinely exceed the standards recommended by the World Health Organization [6]. As a result, there has been an increase in diagnosed incidences of chronic bronchitis, asthma, reduction of pulmonary capacity, and in premature mortality rates among the citizens. The study region, Mexico City and the neighboring areas in main wind direction (SW to NE) includes three different sites (T0, T1, T2): T0 - within MCMA located at Iztapalapa, T1 - at the Universidad Tecnológica de Tecámac in the State of Mexico, T2 in Rancho La Bisnaga, north of Tizayuca in the State of Hidalgo (Figure 2). The designations refer to transport of the urban plume to different points in space and time. The selected VOC represent alkanes, cycloalkanes and aromatics, chloroaromatics, terpenes.

\subsection{Sampling design and measurement method}

Sampling was carried out in indoor and outdoor air using passive sampler (3M OVM 3500, 1986) [14]. A sampling period of four weeks was selected, since an integrative sampling described a mean load relative to personal exposure. Using this procedure, it can be assumed that the human exposure is more selectively described compared with a short time measurement. Indoor samples were collected in kindergartens, schools, offices and in the selected homes of children, while outdoor samples were collected in representative sites parallel to the indoor measurement. The outdoor monitors were placed at rain-protected positions. Indoors, the passive monitors were placed in the middle of the room at a 1.5-2 $\mathrm{m}$ height with a minimum distance of $50 \mathrm{~cm}$ to the ceiling $[7,15]$.

According to their structure and composition the VOC belong to the following groups: alkanes (hexane, heptane, octane, nonane, decane, undecane, dodecane, tridecane); cycloalkanes (methylcyclopentane, cyclohexane, methylcyclohexane); aromatic hydrocarbons (benzene, toluene, ethylbenzene, $\mathrm{m}+\mathrm{p}$-xylene, styrene, o-xylene, 4-ethyltoluene, 3-ethyltoluene, 2-ethyltoluene, naphthalene); chlorinated hydrocarbons (chlorbenzene, trichlorethylene, tetrachlorethylene); terpenes (a-pinene, b-pinene, 2-carene, 3-carene, limonene).

After exposure, the VOCs were desorbed from the adsorption layers (charcoal pads) by means of $1.5 \mathrm{ml}$ of carbon disulfide (with low benzene, from Merck) containing $1 \%$ of methanol. The VOC analysis was performed on a PerkinElmer gas chromatograph with a masspectrometrical detector, equipped with an RTX-1 column (60 m $0.32 \mathrm{~mm}$ I.D., $1.0 \mu \mathrm{m}$ film thickness; Restek). The oven temperature was held at $43{ }^{\circ} \mathrm{C}$ for $5 \mathrm{~min}$, and then programmed to $200{ }^{\circ} \mathrm{C}$ at a rate of $2.5^{\circ} \mathrm{C} \mathrm{min}^{-1}$. The injector temperature was held at $250{ }^{\circ} \mathrm{C}$ as well as the 
transfer line temperature. An electron energy of $70 \mathrm{eV}$ was used for ionization. The source temperature was held at $200{ }^{\circ} \mathrm{C}$. A sample volume of $1 \mu$ was splitless injected. Integrated areas of selected fragment ions from each of the 29 VOCs were obtained with the software Turbomass, Version 4.4 (PerkinElmer) $[7,10]$.

\subsection{Quantification and statistical analysis}

Recovery coefficients were determined by direct injection of a known amount of the standard into a 3M sampler and subsequent extraction with carbon disulfide containing $1 \%$ methanol. The recovery was between $98 \%$ and $102 \%$. For the studied VOCs, the background amounts contained in the monitors and in the carbon disulfide were determined for each charge of the samplers and chemicals and were subtracted from the sample results. The detection limits for the components were estimated as the three-fold standard deviation of five replicate measurements of monitor blanks. For components with blank values too low to be registered, it is usual practice to use the three-fold standard deviation of replicate measurements of a low-level standard solution [15]. The average concentration of each component over the sampling interval (in $\mu \mathrm{g} \mathrm{m}^{-3}$ ) was calculated according to the equation adopted from 3M [14], using the adsorption coefficients in charcoal. The detection limits were found to be between 0.01 and $0.05 \mathrm{mg} \mathrm{m}^{-3}$ regarding a sampling interval of 4 weeks.

A non-parametric method (Mann-Whitney U-Test) was used for statistical analysis of results, according to the non-symmetrical distribution of the data. Statistical analysis and plots of median values were prepared using Statistica 7.1 [17]. A $p$-value below 0.05 was regarded to be statistically significant.

\section{Results and discussion}

\subsection{Total VOCs load}

The concentration levels of the total indoor and outdoor VOC content per study area is shown in Figure $3 a$ and $3 b$.

Significantly higher concentrations of indoor VOCs were observed independent from the study and local area.

\subsection{Indoor-outdoor ratio}

Since most people spend over 80 percent of their time indoors [10], indoor VOCs are thought to be of greater concern considering potential health effects because the indoor concentrations of these compounds are often higher than those typically encountered outdoors. On the one hand the indoor-outdoor ratio (I/O) is generally used to infer penetration to indoor environments and indoor sources [18]. On the other hand this ratio will be determined also by the use of the buildings. It makes a difference whether the building is mainly used for apartments or for public demands. An I/O ratio lower and close to one indicates 
more outdoor sources. Significant differences between indoor and outdoor concentrations indicate mainly indoor sources for the VOC compounds.

The I/O ratio of the apartments in the urban and suburban areas is similar (between 2.5 and 2.7).

The ratio is lower for the schools/offices than for the apartments. This reflects the lower indoor exposure in the public building coming from a reduced use of indoor exposure causing materials and maybe from a reduced redecoration activity but a better air exchange rate.

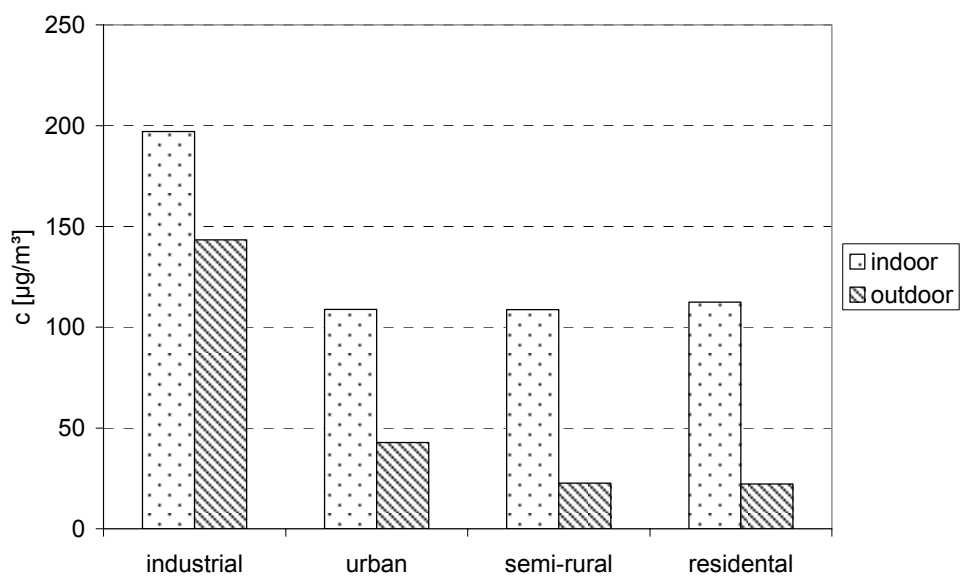

(a)

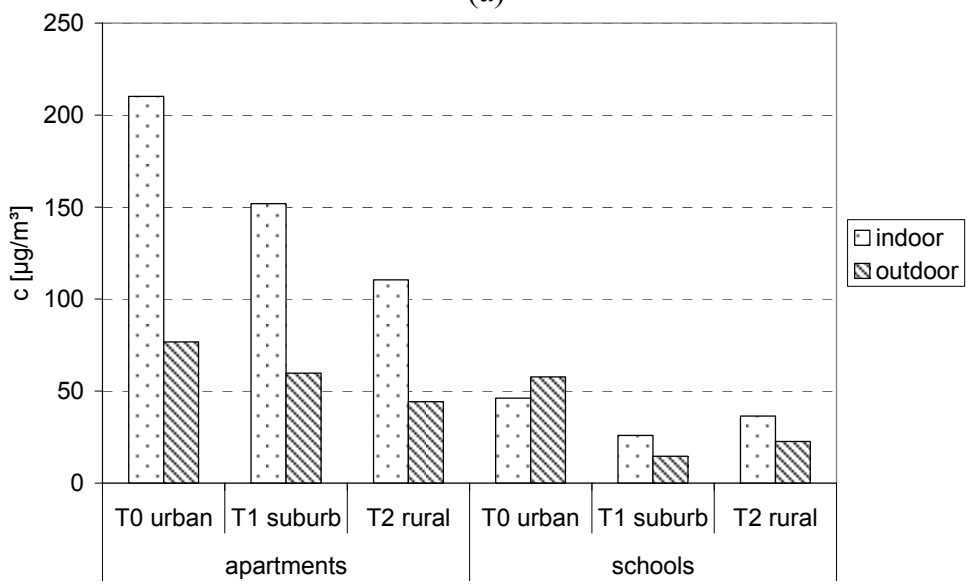

(b)

Figure 3: (a) Indoor and outdoor concentration of VOC (sum of measured VOC) in La Plata and surroundings (mean values). (b) Indoor and outdoor concentration of VOC (sum of measured VOC) in different building types in Mexico City and surroundings (mean values). 
The main sources are the industrial complex and the traffic. The highest outdoor exposure was measured in the industrial area of La Plata following by the traffic dominated exposure in the urban area of Mexico City. The lowest load was recorded in the rural respectively semi-rural sites of both study areas.

\section{Conclusions}

Ambient air in the vicinity of the industrial and urban site is significantly different than the air quality found in the semi-rural and suburban residential areas. Whereas traffic was identified as the main source of outdoor VOC exposure in the urban and residential areas, in the industrial area, outdoor as well indoor air is strongly affected by emissions of the local industry.

Total VOCs in the urban, residential and semi-rural areas are equivalent to those reported for other major cities worldwide, indicating comparable burdens, although non-equivalent distribution patterns could be a result of different lifestyles and habits.

Indoor/outdoor ratios suggest higher indoor burdens in all places and demonstrate an exceptional importance of indoor exposure.

The high outdoor VOC content in the industrial and "high" traffic loaded area, together with the lifestyle quality, very strongly affected the indoor exposure for these inhabitants.

Further research will be necessary to evaluate the environmental impact of VOCs and the assessment of effects of the different volatile compounds on human health.

\section{Acknowledgements}

Parts of this study were supported by the International Bureau of the German Federal Ministry of Education and Research, the Secretary of Science and Technology and Province Research Council of the Province of Buenos Aires (CICPBA), the National Research Council of Argentina (CONICET), the Metropolitan Environmental Commission of México City and the Molina Center for Energy and the Environment. The authors would also like to thank Brigitte Winkler for her excellent assistance in the chemical analyses, and Jephte Cruz for her assistance during the monitoring.

\section{References}

[1] WHO (World Health Organization). Protection of the Human Environment. The health effects of indoor air pollution exposure in developing countries, Geneva, 2004.

[2] Brown, S.K. Volatile organic compounds in new and established buildings in Melbourne, Australia. Indoor Air. 12:55-63, 2002.

[3] Tovalin, H., Whitehead, L. Personal exposure to volatile organic compounds among outdoor and indoor workers in two Mexican cities. Science of the Total Environment. 376, 60-71, 2007. 
[4] Herbarth, O., Rehwagen, M., Ronco, A. The Influence of Localized Emittants on the Concentration of Volatile Organic Compounds in the Ambient Air Measured Close to Ground Level. Environ Toxicol Water Qual. 12:31-37, 1997.

[5] Chan, C., Chan, L., Wang, X., Liu, Y., Lee, Y., Zou, S., Sheng, G., Fu, J. Volatile organic compounds in roadside microenvironments of metropolitan Hong Kong. Atmos Environ. 36 (12):2039-2047, 2002.

[6] SMA - Secretaria del Medio Ambiente. Inventario de contaminantes tóxicos del aire en la ZMVM (MCMA Air toxics inventory). Gobierno del Distrito Federal. México. 2006.

[7] Rehwagen, M., Schlink, U., Herbarth, O. Seasonal cycle of VOCs in apartments. Indoor Air 13:1-9, 2003.

[8] Guo, H., Lee, S., Chan, L., Li, W. Risk assessment of exposure to volatile organic compounds in different indoor environments. Environ Res. 94:5766, 2004.

[9] Son, B., Breysse, P., Yang, W. Volatile organic compounds concentration in residential indoor and outdoor and its personal exposure in Korea. Environ Int. 29:79-85, 2003.

[10] Schlink, U., Rehwagen, M., Damm, M., Richter, M., Borte, M., Herbarth, O. Seasonal cycle of indoor-VOCs: comparison of apartments and cities. Atmos Environ. 38: 1181-1190, 2004.

[11] Jones, A. Indoor air quality and health. Atmos Environ. 33:4535-4564, 1999.

[12] Watson, J., Chow, J., Fujita, E. Review of volatile organic compound source apportionment by chemical mass balance. Atmos Environ. 35:15671584, 2001.

[13] Guo, H., Lee, S., Li, W., Cao, J. Source characterization of BTEX in indoor microenvironments in Hong Kong. Atmos Environ. 37:73-82, 2003.

[14] 3M Deutschland GmbH Technische Informationen 3M Monitore, 1986

[15] Begerow J, Jermann E, Kelles T, Ranft U, Dunemann L. Passive sampling for Volatile Organic Compounds (VOCs) in air at environmentally relevant concentration levels. Fresenius Journal of Analytical Chemistry 351: 549554, 1995.

[16] MILAGRO-Factsheet 2006: http://www.eol.ucar.edu/projects/milagro/ media/MILAGRO-Factsheet-Final.pdf

[17] StatSoft, Inc. (2005). STATISTICA für Windows [Software-System für Datenanalyse] Version 7.1. Www.statsoft.com

[18] Tang, J., Chan, C.Y., Wang, X., Chan, L.Y., Sheng, G., Fu, J. Volatile organic compounds in a multi-storey shopping mall in Guangzhou, South China. Atmos Environ. 39:7374-7383, 2005. 